\title{
The influence of the anisotropic stress state on the intermediate strain properties of granular material
}

\author{
M. GOUDARZY*, D. KÖNIG*, J. C. SANTAMARINA† and T. SCHANZ*
}

\begin{abstract}
This paper shows the effect of anisotropic stress state on intermediate strain properties of cylindrical samples containing spherical glass particles. Tests were carried out with the modified resonant column device available at Ruhr-Universität Bochum. Dry samples were subjected to two anisotropic stress states: $(a)$ cell pressure, $\sigma_{\mathrm{h}}^{\prime}$, constant and vertical stress, $\sigma_{\mathrm{v}}^{\prime}$, increased (stress state GB-I) and $(b) \sigma_{\mathrm{v}}^{\prime} / \sigma_{\mathrm{h}}^{\prime}$ equal to 2 (stress state GB-II). The experimental results revealed that the effect of stress state GB-II on the modulus and damping ratio was more significant and obvious than stress state GB-I. The effect of the anisotropic stress state was explained through the impact of confining pressure and anisotropic stress components on the stiffness and damping ratio. The results showed that: $(a) G(\gamma)$ increased, $\eta(\gamma)$ decreased and their strain non-linearity decreased with an increase in the confining pressure component $\sigma_{\mathrm{v}}^{\prime} \sigma_{\mathrm{h}}^{\prime} ;(b) G(\gamma)$ decreased, $\eta(\gamma)$ increased and their strain non-linearity increased with an increase in the anisotropic stress component, $\sigma_{\mathrm{v}}^{\prime} / \sigma_{\mathrm{h}}^{\prime}$. The analysis of results revealed that reference shear strain was also affected by anisotropic stress state. Therefore, an empirical relationship was developed to predict the reference shear strain, as a function of confining pressure and anisotropic stress components. Additionally, the damping ratio was written as a function of the minimum damping ratio and the reference shear strain.
\end{abstract}

KEYWORDS: anisotropy; deformation; laboratory tests; settlement; stiffness; vibration

\section{INTRODUCTION}

The shear modulus and damping ratio are key parameters to evaluate the response of soil elements subjected to cyclic loading. These parameters are significantly affected by the magnitude of deformation or vibration. In addition, experimental studies over the past few decades have shown that the modulus degradation and damping ratio curves are significantly affected by confining pressure (e.g. Tatsuoka et al., 1978; Kokusho, 1980; Seed et al., 1984). Experimental results have shown the independency of the stiffness ratio $\left(G(\gamma) / G_{\max }\right)$ and damping ratio on the density of sample in granular material (e.g. Tatsuoka et al., 1978; Kokusho, 1980; Wichtmann \& Triantafyllidis, 2013).

The small- and intermediate-strain properties of granular materials not only depend on the confining pressure and the amplitude of the shear strain, but might also depend on the state of stress present in soil elements. From experimental studies, Drnevich (1978) concluded that the increase of damping ratio with the initial shear stress was not significant. Tatsuoka et al. (1979) performed a series of cyclic torsional tests to evaluate the impact of static stress conditions on the small-strain properties of Toyoura sand. From the experimental results, they concluded that the impact of stress ratio on damping ratio was not significant, when the confining pressure was constant and the vertical pressure was variable. Santamarina \& Cascante (1996) reported that the wave velocity increased slightly with an increase in the stress ratio, but the effect of stress ratio on $\eta_{\text {min }}$ was not significant.

Manuscript received 8 July 2016; revised manuscript accepted 9 June 2017.

Discussion on this paper is welcomed by the editor.

* Ruhr-Universität Bochum, Bochum, Germany.

$\uparrow$ King Abdullah University of Science and Technology, Thuwal, Saudi Arabia.
Empirical relations were also developed and modified to predict the modulus degradation and damping ratio in soil samples subjected to isotropic loading. Hardin \& Drnevich (1972b) showed that the strain dependency of the shear modulus can be presented with a hyperbolic curve in soil material. They proposed a well-known empirical relation (equation (1)) to predict the non-linear behaviour of the soil element. Hardin's relation is based on the maximum shear modulus and reference shear strain.

$$
\frac{G(\gamma)}{G_{\max }}=\frac{1}{1+\left(\gamma / \gamma_{\mathrm{r}}\right)}
$$

where $G_{\max }$ is the maximum shear modulus, $\gamma$ is shear strain and $\gamma_{\mathrm{r}}$ is the reference shear strain.

The reference shear strain, $\gamma_{\mathrm{r}}$, is essential for defining hyperbolic curves in stress-strain or stiffness-strain spaces. With regard to Hardin \& Drnevich (1972a), $\gamma_{r}$ is equal to the maximum shear stress, $\tau_{\max }$, over the maximum shear modulus, $G_{\max }$ (equation (2)).

$$
\gamma_{\mathrm{r}}=\frac{\tau_{\max }}{G_{\max }}
$$

where $G_{\max }$ is the maximum shear modulus and $\tau_{\max }$ is the maximum shear strength (Hardin \& Drnevich, 1972a).

Hardin \& Drnevich (1972a) reported that $\tau_{\text {max }}$ depends on the initial state of stress in the soil. They showed that, for initial geostatic stress conditions, with the shear stress applied to horizontal or vertical planes, $\tau_{\max }$, is related to the strength envelope of the soils, and can be written in the form of equation (3).

$$
\tau_{\max }=\sigma_{\mathrm{v}}^{\prime}\left(\left\{\left[\frac{1+\left(\sigma_{\mathrm{h}}^{\prime} / \sigma_{\mathrm{v}}^{\prime}\right)}{2}\right] \sin (\phi)\right\}^{2}-\left[\frac{1-\left(\sigma_{\mathrm{h}}^{\prime} / \sigma_{\mathrm{v}}^{\prime}\right)}{2}\right]^{2}\right)^{1 / 2}
$$

where $\phi$ is the friction angle, and $\sigma_{\mathrm{h}}^{\prime}$ and $\sigma_{\mathrm{v}}^{\prime}$ are the confining and vertical pressures, respectively. 
Hardin \& Drnevich (1972a) proposed equation (4) to predict the modulus degradation.

$$
\frac{G(\gamma)}{G_{\max }}=\frac{1}{1+\left(\gamma / \gamma_{\mathrm{r}}\right)\left\{1+a \exp \left[-b\left(\gamma / \gamma_{\mathrm{r}}\right)\right]\right\}}
$$

where $a$ and $b$ are fitting curve parameters and $\gamma_{\mathrm{r}}$ is the reference shear strain.

For the samples subjected to the anisotropic stress state, Tatsuoka et al. (1979) compared the value of $\gamma_{\mathrm{r}}$ determined from the experimental results with the $\gamma_{\mathrm{r}}$ obtained using equations (2) and (3). They found that $\gamma_{\mathrm{r}}$ from the experimental results was not consistent with the value obtained from equations (2) and (3).

Stokoe et al. (1999) proposed equation (5) to capture the effect of the confining pressure on $\gamma_{\mathrm{r}}$, where $\gamma_{\mathrm{r}}$ is $\gamma$ at $G(\gamma) / G_{\max }=0.5$

$$
\gamma_{\mathrm{r}}=\gamma_{\mathrm{r} 1}\left[\frac{p^{\prime}}{p_{\mathrm{a}}}\right]^{n}
$$

where $\gamma_{\mathrm{r} 1}$ is the reference shear strain when the confining pressure is equal to $100 \mathrm{kPa} ; p_{\mathrm{a}}$ is the atmospheric pressure (assumed as $100 \mathrm{kPa}$ ); and $n$ is the stress exponent.

Damping ratio is often formulated as a function of $G(\gamma) / G_{\max }$ (e.g. Hardin \& Drnevich, 1972a, 1972b; Tatsuoka et al., 1978; Ishihara, 1996; Zhang et al., 2005)

$$
\eta(\gamma)-\eta_{\min }=c_{1}\left[\frac{G(\gamma)}{G_{\max }}\right]^{2}-c_{2}\left[\frac{G(\gamma)}{G_{\max }}\right]+\left(c_{2}-c_{1}\right)
$$

where $\eta_{\min }$ is the minimum damping ratio and $c_{1}$ and $c_{2}$ are the constant parameters.

However, soil elements may be subjected to more complicated stress states in comparison with the stress conditions applied in the existing studies on intermediate strain properties that have been conducted up to now. Also, there is not any empirical relation that can predict the modulus degradation curve and, consequently, the damping ratio curve for granular material subjected to anisotropic stress states. Therefore, additional systematic studies are essential to assess the effect of anisotropic stress state on modulus degradation and damping ratio curves and their empirical relationships.

Micromechanical simulations with the discrete-element method (DEM) have mostly been performed on granular packings containing spherical particles (e.g. Cundall \& Strack, 1979; Ng \& Petrakis, 1996; Magnanimo et al., 2008; Gu \& Yang, 2013; O'Donovan et al., 2015). The data from micromechanical simulations are helpful for the interpretation of these experimental results. Therefore, spherical glass particles were adopted in this experiment to study the influence of the anisotropic stress state on intermediate properties of granular materials. Ishibashi et al. (1991) compared the anisotropic behaviour of Ottawa sand with glass beads. They reported that both materials showed very similar behaviour and concluded that the assemblage of glass spheres can be effectively used to study the state and evolution of the fabric of these types of granular materials. Therefore, the results from this experiment may be extended to the interpretation of the anisotropic behaviour of natural soils.

Numerous studies have been conducted to assess the effect of anisotropic stress state on $G_{\max }$ using bender element and resonant column on sands (e.g. Yu \& Richart, 1984; Santamarina \& Cascante, 1996; Sadek et al., 2007; Wang \& Mok, 2008) or glass beads (e.g. Yanagisawa, 1983; Ishibashi et al., 1991). Therefore, this study focuses on the effect of anisotropic stress state on intermediate strain properties.

The resonant column device was used to evaluate the effect of the anisotropic stress state on the modulus degradation and damping ratio in granular material. The results presented were used to extend an empirical relation to predict the value of $\gamma_{\mathrm{r}}$ and, consequently, modulus and damping ratio curves in the samples subjected to the anisotropic stress state.

This paper is divided into five main sections: in the first section, the experimental programme is discussed briefly. In the second section, the effect of the stress ratio on the modulus degradation and damping ratio of glass bead packing are presented. Then, the effect of the stress ratio on $\gamma_{r}$ is assessed for different anisotropic stress states. In the fourth section, the empirical relations are introduced to predict the reference shear strain for samples subjected to anisotropic stress state, and finally, in the fifth section, the observed experimental results are discussed from a microscopic perspective.

\section{EXPERIMENTAL PROGRAMME}

The experimental programme comprises four parts: the apparatus, material properties, boundary conditions or stress states, and the experimental procedure.

\section{Apparatus}

The resonant column device at Ruhr-Universität Bochum was used to perform test on soils subjected to anisotropic stress states (Fig. 1). The Bochum resonant column device is based on the rotational vibration of a cylindrical sample with given initial dimensions to determine the rotational resonant frequency (Wichtmann et al., 2001). In the Bochum resonant column device, two mini-shakers are mounted on the top of the sample to apply a sinusoidal rotational vibration to the top of the sample. The generated rotational excitation forces were controlled using transducers which were installed on the shakers in both sides of the actuator. In addition, the rotational displacement of the specimen was controlled by transducers, which were mounted at the corners of the actuator. Both of the received signals from transducers (force and displacement signals) were visualised using the oscilloscope device. The resonant frequency was detected when the phase difference between received signals was $\pi / 2$.

Different vibration amplitudes and consequently different ranges of strain are applied on the top of the sample by increasing the amplitude of the rotational excitation. Equation (7) shows the governing equation to calculate the amplitude of the shear strain in the Bochum resonant column device (Wichtmann et al., 2001; Wichtmann \& Triantafyllidis, 2013) 


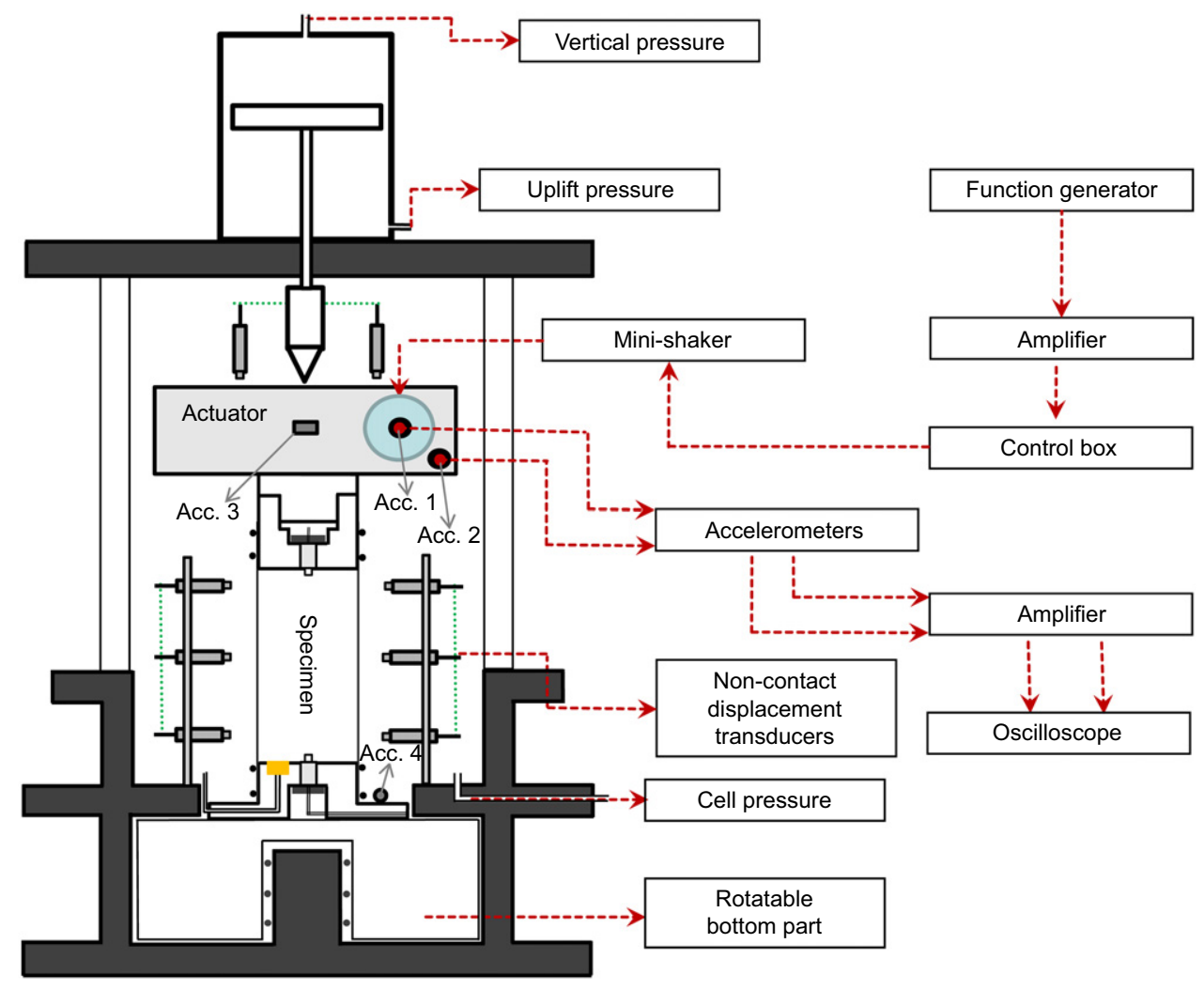

Fig. 1. Schematic sketch of the Bochum resonant column device for performing test on samples subjected to anisotropic stress states

where $\theta_{\max }$ is the maximum rotation at the top of the sample. $\alpha$ is equal to $\omega L / v_{\mathrm{s}}, \omega$ is the rotational frequency, $v_{\mathrm{s}}$ is the shear wave velocity, $J_{0}$ and $J_{\mathrm{L}}$ are polar mass moments of inertia for the bottom and top of the sample and $J$ is the polar mass moment of inertia of the sample. Equation (7) shows that the shear strain is a function of the radius, $r$. Therefore, to eliminate the effect of $r$, the shear strain was normalised with respect to the volume of the sample as

$$
\bar{\gamma}=\frac{D}{3 L} \theta_{\max }\left[1-\frac{1}{\cos (\alpha)-\left(J_{0} / J\right) \alpha \sin (\alpha)}\right]
$$

where $\bar{\gamma}$ is the normalised shear strain with respect to the volume of the sample, $D$ is the diameter of the sample, $L$ is the length of the sample. $\bar{\gamma}$ is simply shown by $\gamma$ in the analysis of the test results in this paper. The shear strain amplitudes that can be tested in the device lie in the range of $5 \times 10^{-7}$ to $5 \times 10^{-4}$.

Furthermore, seven non-contact displacement transducers were mounted around and on top of the sample to measure the radial and vertical deformations of samples due to the loading and during resonant column tests (Fig. 1).

To apply an additional vertical stress inside the sample, the actuator was loaded in the vertical direction by a doubleacting pressure cylinder. The load of the cylinder was transferred through a loading bar, a hardened steel tip, to a hardened steel plate which was mounted at the central axis on the actuator. The influence of the loading equipment on the dynamic behaviour of the system and its interaction with the actuator was evaluated using numerical and experimental procedures (Goudarzy, 2015).

The energy method is used to calculate damping ratio of soil samples using the Bochum resonant column device (Wichtmann et al., 2001; Wichtmann \& Triantafyllidis, 2013). In this method, damping is determined as a ratio of the dissipated energy $(\Delta W)$ divided by $4 \pi$ times the total energy $(W)$. Calibration of the device for damping ratio was done with an aluminium sample using bandwidth, free vibration decay curve and energy methods (Goudarzy, 2015).

\section{Material properties}

Glass bead samples (10 cm dia. and $20 \mathrm{~cm}$ high) with $G_{\mathrm{s}}=2.55, e_{\max }=0.618, e_{\min }=0.578$ and $d=1.10-1.65 \mathrm{~mm}$, were used for this experimental programme (Fig. 2).

The stress-strain and volumetric behaviour of the adopted material were essential for explaining the results from resonant column test. Thus, triaxial testing was conducted on the dense samples with a relative density of $90 \%$ and confining pressure of $200 \mathrm{kPa}$. The results of the triaxial test are presented in Fig. 3. This figure shows the well-known behaviour of dense granular materials during a drained triaxial loading path.

\section{Stress path}

Resonant column tests were conducted on the dry samples subjected to two anisotropic stress states: $(a)$ anisotropic stress state GB-I, confining pressure, $\sigma_{\mathrm{h}}^{\prime}$, was kept constant and $\sigma_{\mathrm{v}}^{\prime}$ was increased up to $\sigma_{\mathrm{v}}^{\prime} / \sigma_{\mathrm{h}}^{\prime}=2 ;(b)$ anisotropic stress

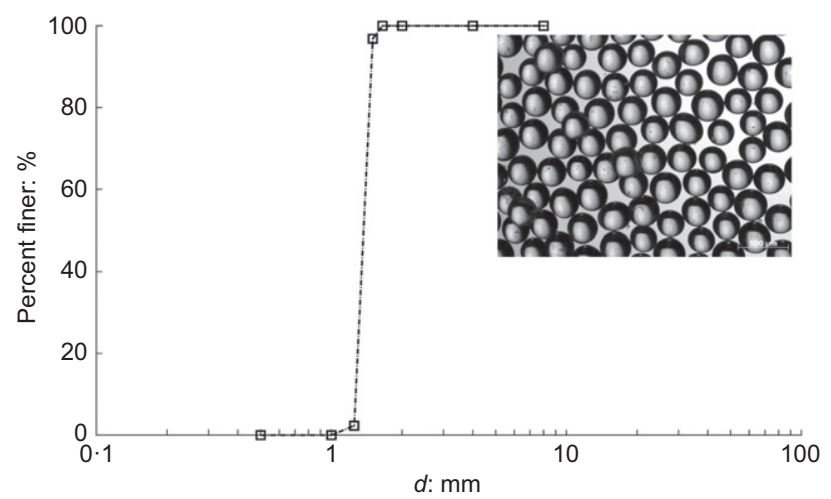

Fig. 2. Grain size distribution and microscopic image of the glass beads adopted for the study 


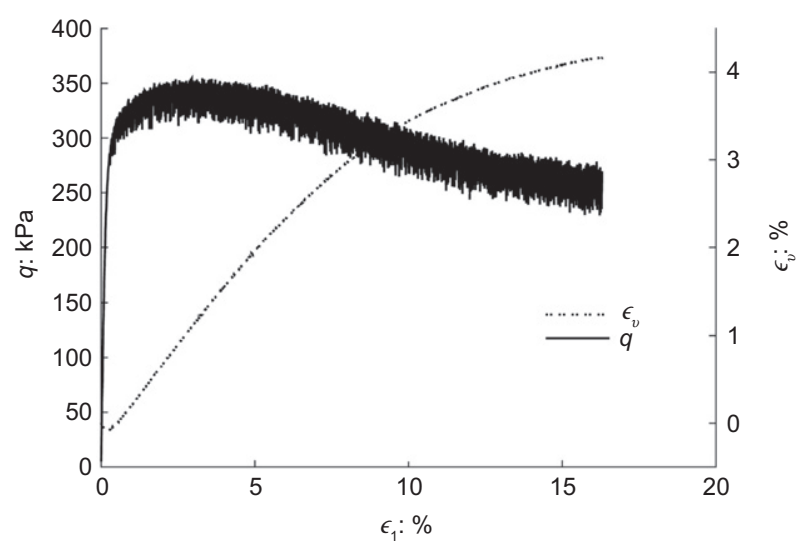

Fig. 3. Triaxial test results of the glass beads adopted, $e_{0}=0 \cdot 59$ and confining pressure of $200 \mathrm{kPa}$

state GB-II, $\sigma_{\mathrm{v}}^{\prime} / \sigma_{\mathrm{h}}^{\prime}$ was equal to two for this stress state. Fig. 4 shows the adopted stress states for this experimental programme. For stress state GB-I, vertical stress $\left(\sigma_{\mathrm{v}}^{\prime}\right)$ was increased and horizontal stress $\left(\sigma_{\mathrm{h}}^{\prime}\right)$ was kept constant at $200 \mathrm{kPa}$ during the resonant column test. For stress state GB-II, the stress ratio $\left(K=\sigma_{\mathrm{v}}^{\prime} / \sigma_{\mathrm{h}}^{\prime}=2\right)$ was constant. In this stress state, the horizontal stress $\left(\sigma_{\mathrm{h}}^{\prime}\right)$ was equal to 150,200 and $300 \mathrm{kPa}$.

\section{Experimental procedure}

Dense samples with a relative density of $90 \%\left(D_{\mathrm{r}}=90 \%\right)$ were prepared by the dry pluviation method. The maximum vacuum of $50 \mathrm{kPa}$ was applied through the top and bottom caps to stabilise the sample before assembling the resonant column device. Afterwards, the vacuum was reduced and the confining pressure was increased gradually. The specimens were subjected to the target isotropic stress state of 100, 200, 300 and $400 \mathrm{kPa}$ for performing resonant column tests. For anisotropic stress state GB-I, the confining pressure was kept constant at $200 \mathrm{kPa}$ and the vertical load was increased up to the target vertical stress (in this study, vertical stress was increased to $250,300,350$ and $400 \mathrm{kPa}$ ). For anisotropic stress state of GB-II, the confining pressure $\left(\sigma_{\mathrm{h}}^{\prime}\right)$ was increased up to the target isotropic pressure $(150,200$ and $300 \mathrm{kPa})$ and then the vertical stress was increased to get the stress ratio $\left(\sigma_{\mathrm{v}}^{\prime} / \sigma_{\mathrm{h}}^{\prime}\right)$ to equal two. After consolidation of the sample at the desired stress conditions, the amplitude of excitation was increased to get the resonant frequency and, consequently,

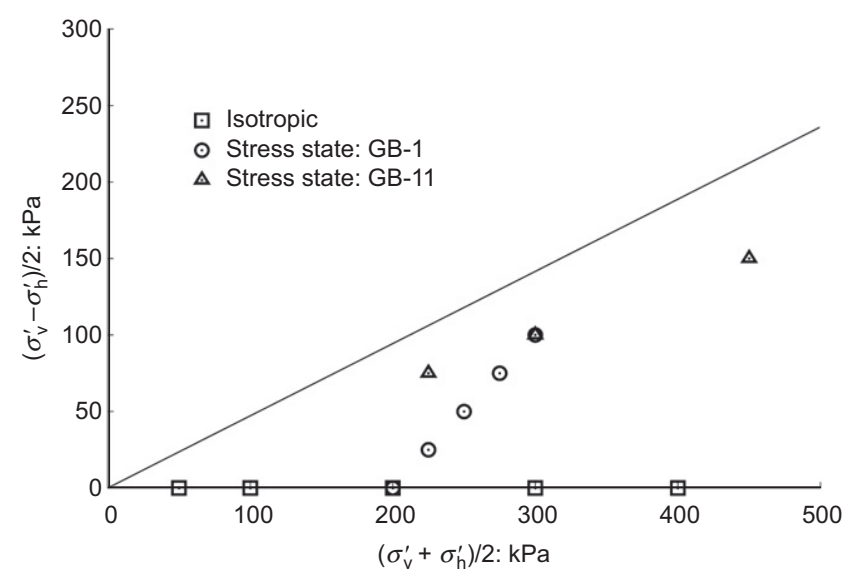

Fig. 4. Stress states adopted in the resonant column tests with glass beads the stiffness and damping ratio at different amplitudes of excitation.

This experiment has been done on dry samples; therefore, the effective stress is replaced by total stress in the next sections.

\section{TEST RESULTS}

The effect of induced anisotropy on $\mathrm{G}(\gamma)$ and $\eta(\gamma)$

The resonant column test results of the glass bead samples are presented in this section. This section is divided into two main parts: in the first part, the results of isotropic stress state are presented and afterwards, the results of anisotropic stress state are presented in the second part.

Isotropic loading. It is well known that, at a given strain amplitude, the shear modulus, $G(\gamma)$, and modulus ratio, $G(\gamma) / G_{\max }$, increase with an increase in the confining pressure, and the damping ratio decreases with an increase in the confining pressure. The observed experimental results (Figs 5(a)-5(c)) also show the dependency of modulus degradation and the damping ratio on the isotropic confining pressure and the amplitude of shear strain, which is in line with the observed results in the literature.

Figure 6 shows that the shear modulus is constant and equal to the maximum shear modulus $\left(G(\gamma) / G_{\max }=1\right)$ up to a certain shear strain termed the threshold shear strain, $\gamma_{\mathrm{et}} \cdot \gamma_{\mathrm{et}}$ is a value between $2 \times 10^{-6}$ and $5 \times 10^{-6}$ for glass beads subjected to an isotropic stress state. This figure reveals that $\gamma_{\mathrm{et}}$ increases with $p$ for samples subjected to an isotropic stress state.

Anisotropic loading. Figures 7(a) and 7(b) show the effect of shear strain on the shear modulus of glass bead samples with the relative density of $90 \%$ and subjected to anisotropic stress states GB-I and GB-II, respectively. Fig. 7(a) shows that the shear stiffness increases with an increase in the vertical stress $\left(\sigma_{\mathrm{v}}\right)$ up to the vertical stress of $350 \mathrm{kPa}$, and then the shear stiffness decreases with a further increase in the vertical stress, further explained in the section entitled 'Empirical relationships'. However, for stress state GB-II, the shear stiffness increases with an increase in the confining and vertical stress (Fig. 7(b)). Additionally, the results presented show the dependency of the shear stiffness on the shear strain in samples subjected to the anisotropic stress states GB-I and GB-II.

Figures 8(a) and 8(b) show the effect of stress-induced anisotropy on the damping ratio plotted against the shear strain for stress states GB-I and GB-II, respectively. For stress state GB-I, the experimental test data show that damping ratio decreases slightly with an increase in the vertical stress up to a vertical stress of $350 \mathrm{kPa}$ and it then increases at a vertical stress of $400 \mathrm{kPa}$ (Fig. 8(a)). For stress path II, however, the damping ratio decreases with an increase in the confining and vertical stress (Fig. 8(b)). Fig. 8 shows that the effect of the anisotropic stress state on the damping ratio for stress state GB-II is more obvious than for stress state GB-I. The effect of anisotropic stress state on the modulus ratio $\left(G(\gamma) / G_{\max }\right)$ is presented in Figs 9(a) and 9(b) for stress states I and II, respectively. For stress state GB-I, Fig. 9(a) reveals that the modulus ratio increases slightly with an increase in the vertical stress up to a vertical stress of $350 \mathrm{kPa}$ and it then decreases at the vertical stress of $400 \mathrm{kPa}$. Fig. 9(b) shows that modulus ratio increases significantly with an increase in the confining pressure and the vertical stress. Fig. 9 reveals that the effect of the anisotropic stress states on $G / G_{\max }$ for stress state GB-II is more significant than for stress state GB-I. 


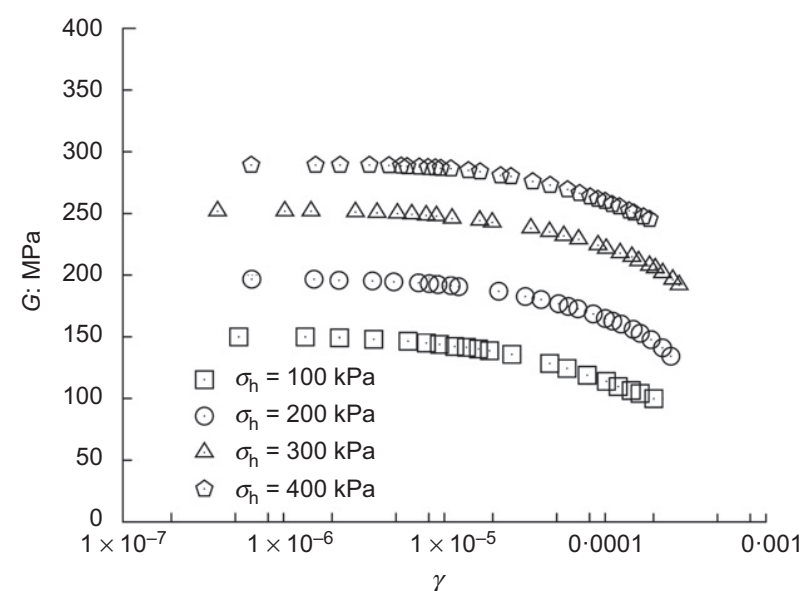

(a)

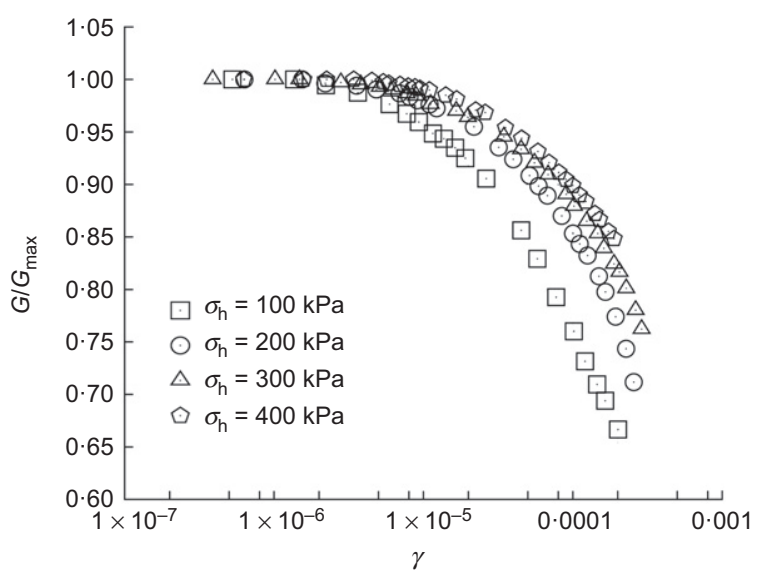

(b)

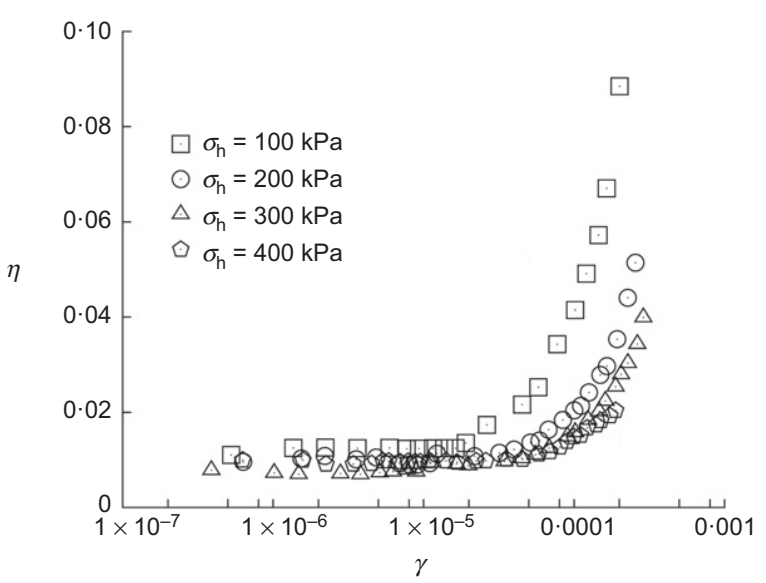

(c)

Fig. 5. The effect of isotropic confining pressure on: (a) shear modulus, $G(\gamma)$; (b) modulus ratio, $G(\gamma) / G_{\text {max }}$; (c) damping ratio, $\eta(\gamma)$ of the adopted materials, $e_{0}=0.59$

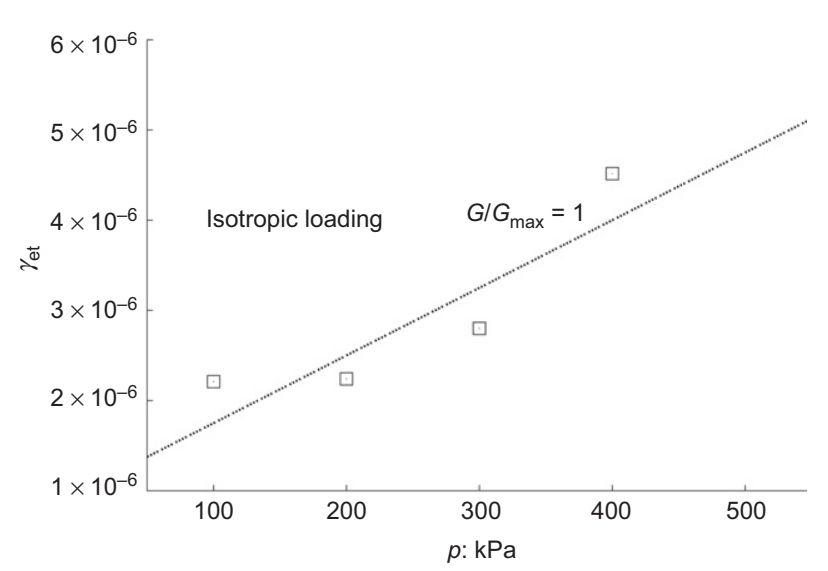

Fig. 6. $\gamma_{\mathrm{et}}$ plotted against $p$ for sample subjected to isotropic stress state

\section{COMPARISON WITH PUBLISHED DATA}

The measured stiffness ratio, $G(\gamma) / G_{\max }$, and the damping ratio, $\eta(\gamma)$, from this experiment were compared with previously published data ranges for silts and sands (Figs 10(a) and 10(b)). The results show that the data fit with the range proposed for granular materials. Fig. 10(a) shows that $G(\gamma) / G_{\max }$ curves for glass bead samples are close to the upper line proposed by Rollins et al. (1998) for sands. This could be due to the poor grain size distribution of the adopted material. This is in agreement with Wichtmann \&
Triantafyllidis (2013), who observed that, for poorly graded sands, the curves of $G / G_{\max }$ were above the proposed range for $G / G_{\max }$ of sands.

\section{EMPIRICAL RELATIONSHIPS}

To predict the $G(\gamma)$ using equations (1) or (4) the value of $\gamma_{\mathrm{r}}$ must be determined. The value of $\gamma_{\mathrm{r}}$ can be determined by two methods: (a) using equations (2) and (3) for isotropic loading; (b) back analysis, fitting equation (1) to the test data in the $G(\gamma) / G_{\max }-\gamma$ plot to obtain the maximum $R^{2}$ (Zhang et al., 2005).

In the first method, with the triaxial test results, the value of the friction angle $(\phi)$ for dense glass bead packing was approximately $30^{\circ}$. Based on equations (2) and (3), for a dense sample at confining pressure of $100 \mathrm{kPa}$, the value of $\gamma_{\mathrm{r}}$ (so-called $\gamma_{\mathrm{r} 1}$ ) was $3 \cdot 31 \times 10^{-4}$.

In the second method, the value of $\gamma_{\mathrm{r}}$ was determined by fitting the hyperbolic function (equation (1)) to the $G(\gamma) / G_{\max }-\gamma$ curves (Zhang et al., 2005). The value of $\gamma_{\mathrm{r} 1}$ was equal to $3 \cdot 56 \times 10^{-4}$ with this method.

Tatsuoka et al. (1979) reported that equations (2) and (3) are not applicable to estimate the value of $\gamma_{\mathrm{r}}$ for samples subjected to an anisotropic stress state. As an example, for a sample subjected to the stress state of GB-II and cell pressure of $200 \mathrm{kPa}, \gamma_{\mathrm{r}}$ using equations (2) and (3) will be equal to $5 \times 10^{-4}$. If this value is used as $\gamma_{\mathrm{r}}$ in equation (1) to predict the $G(\gamma) / G_{\max }-\gamma$ curve, the value of $R^{2}$ will be 0.83 (in comparison with the measured results for this stress state). 


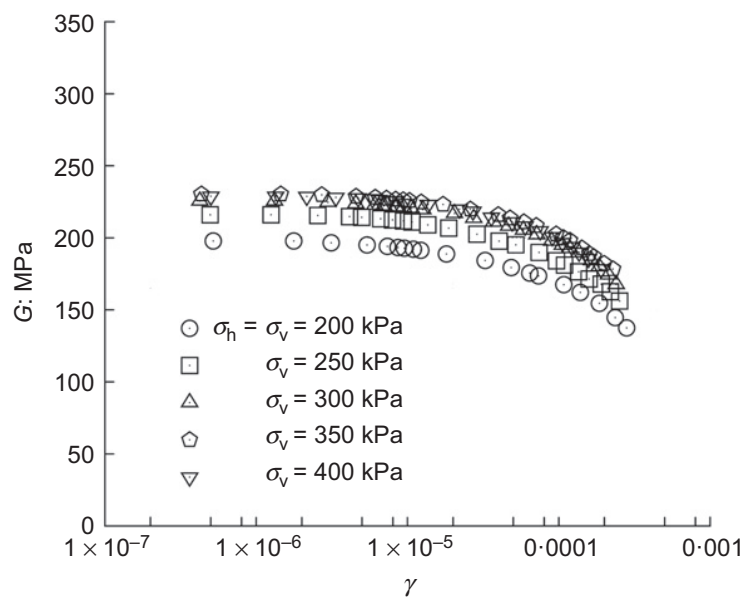

(a)

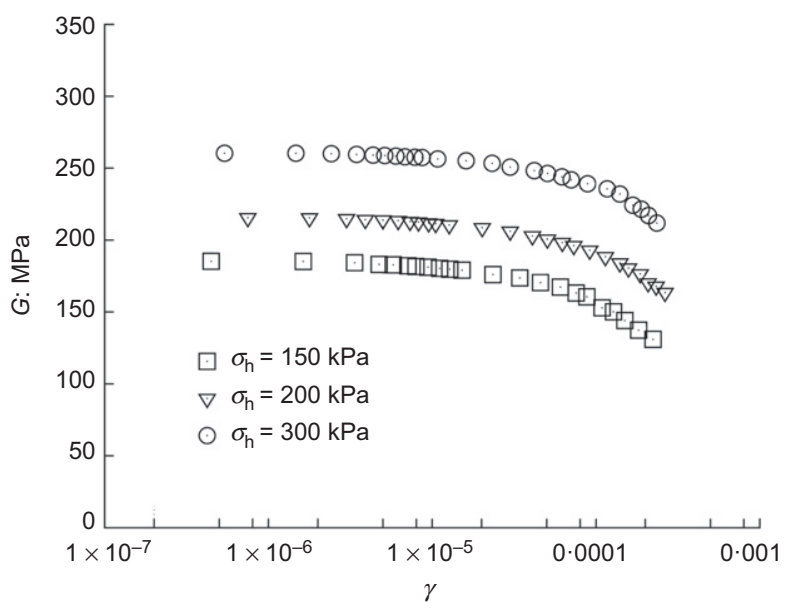

(b)

Fig. 7. The effect of stress-induced anisotropy on the shear modulus, $G(\gamma), e_{0}=0 \cdot 59$ : (a) stress state GB- I; (b) stress state GB-II

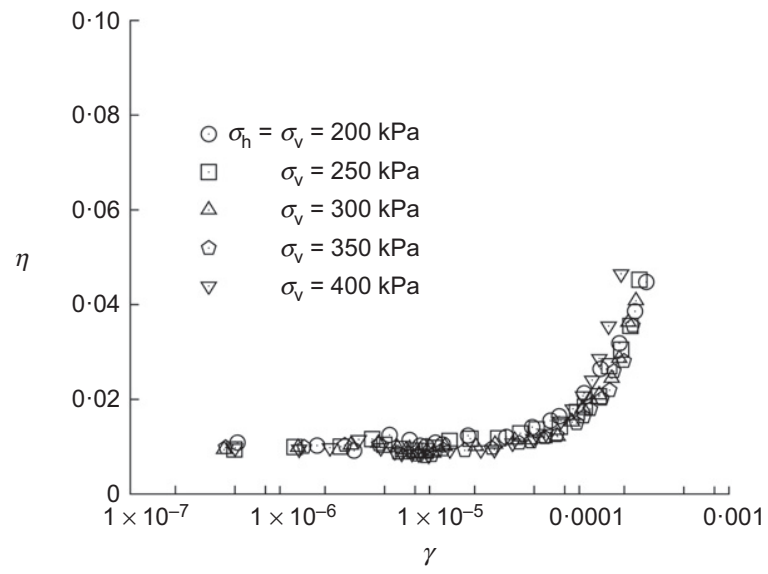

(a)

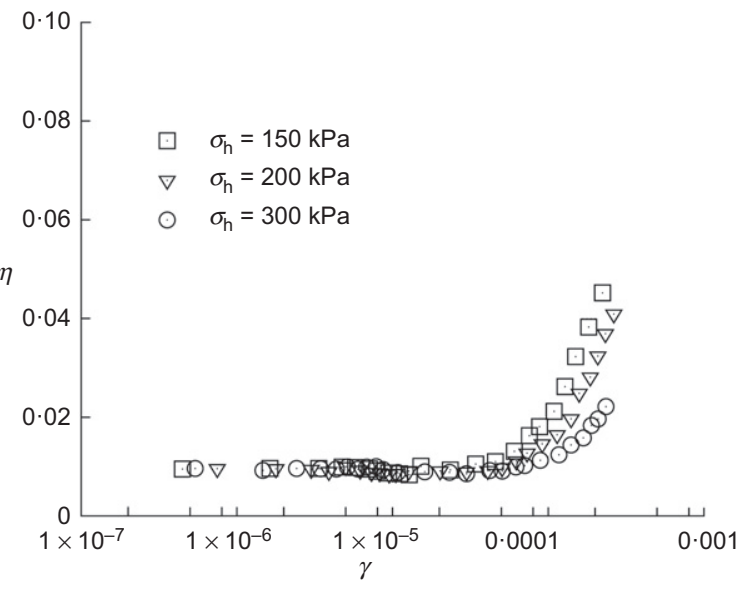

(b)

Fig. 8. The effect of anisotropic stress state on damping ratio, $\eta(\gamma), e_{0}=0 \cdot 59$ : (a) stress state GB-I; (b) stress state GB-II

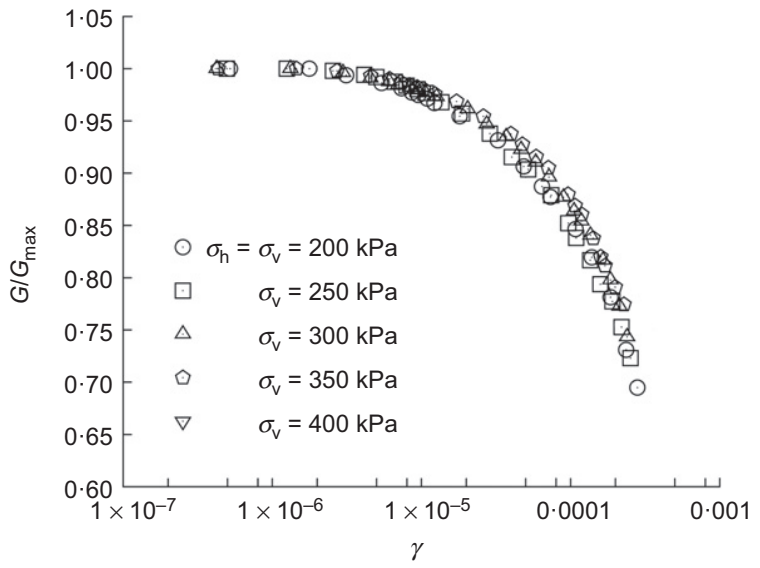

(a)

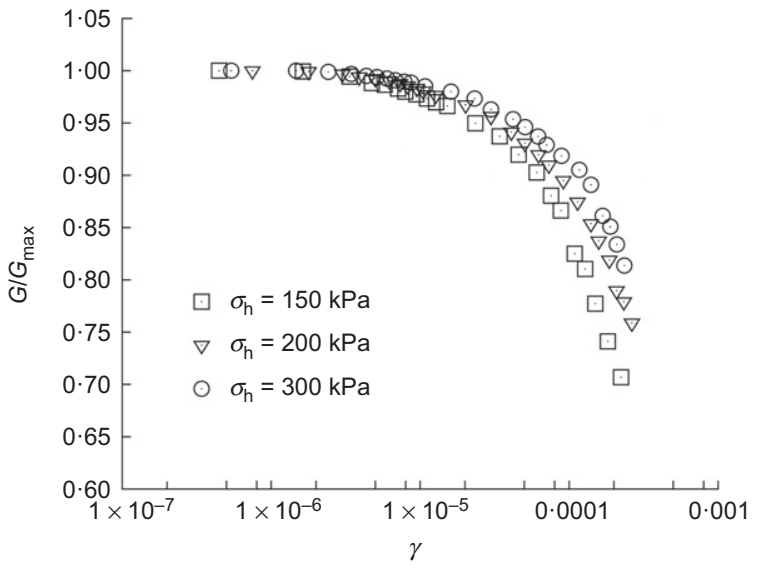

(b)

Fig. 9. The effect of the anisotropic stress state on the modulus ratio, $G(\gamma) / G_{\max }, e_{0}=0 \cdot 59$ : (a) stress state GB-I; (b) stress state GB-II

However, $\gamma_{\mathrm{r}}$ using the second method will be equal to $7 \cdot 88 \times 10^{-4}\left(R^{2}=0.99\right)$.

The reference shear strain is employed to define hyperbolic curves using equations (1) or (4). However, there is no suitable method to estimate $\gamma_{\mathrm{r}}$ for samples subjected to an anisotropic stress state, as also reported by Tatsuoka et al. (1979). The back analysis of equation (1) (second method) was used to determine $\gamma_{\mathrm{r}}$ for samples subjected to isotropic and anisotropic stress states. The measured $\gamma_{\mathrm{r}}$ have been drawn against the compression pressure component, $\sigma_{\mathrm{v}} \sigma_{\mathrm{h}}$, 


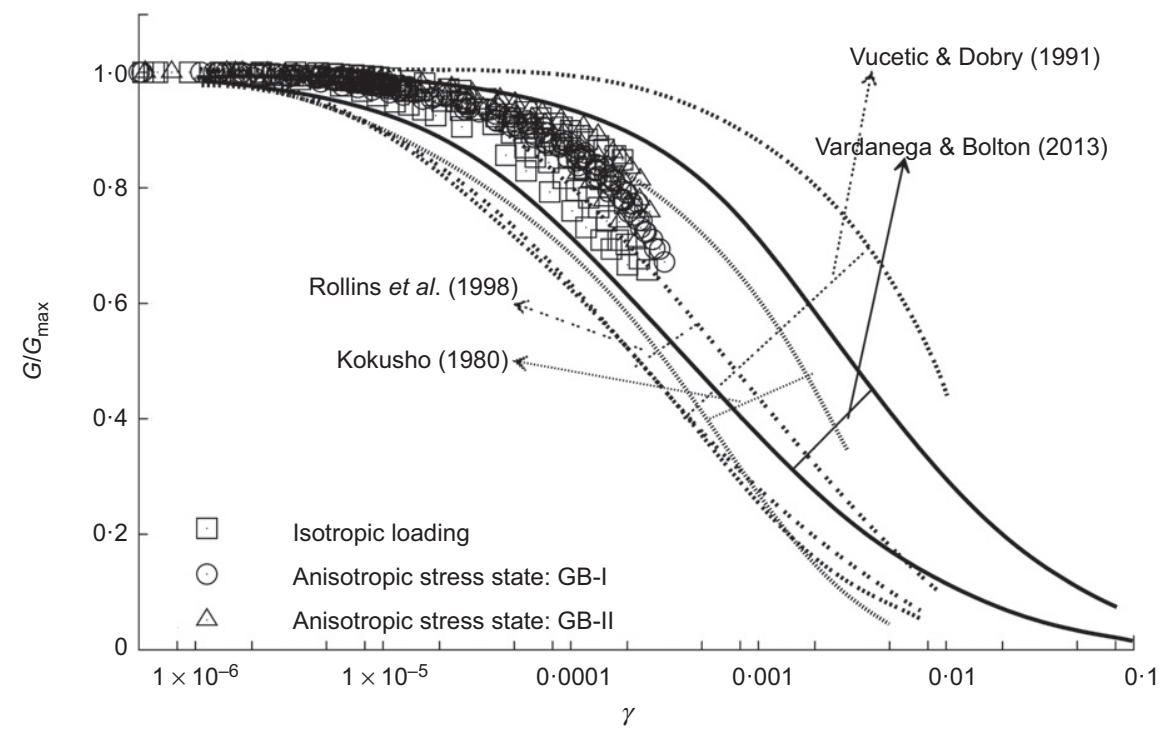

(a)

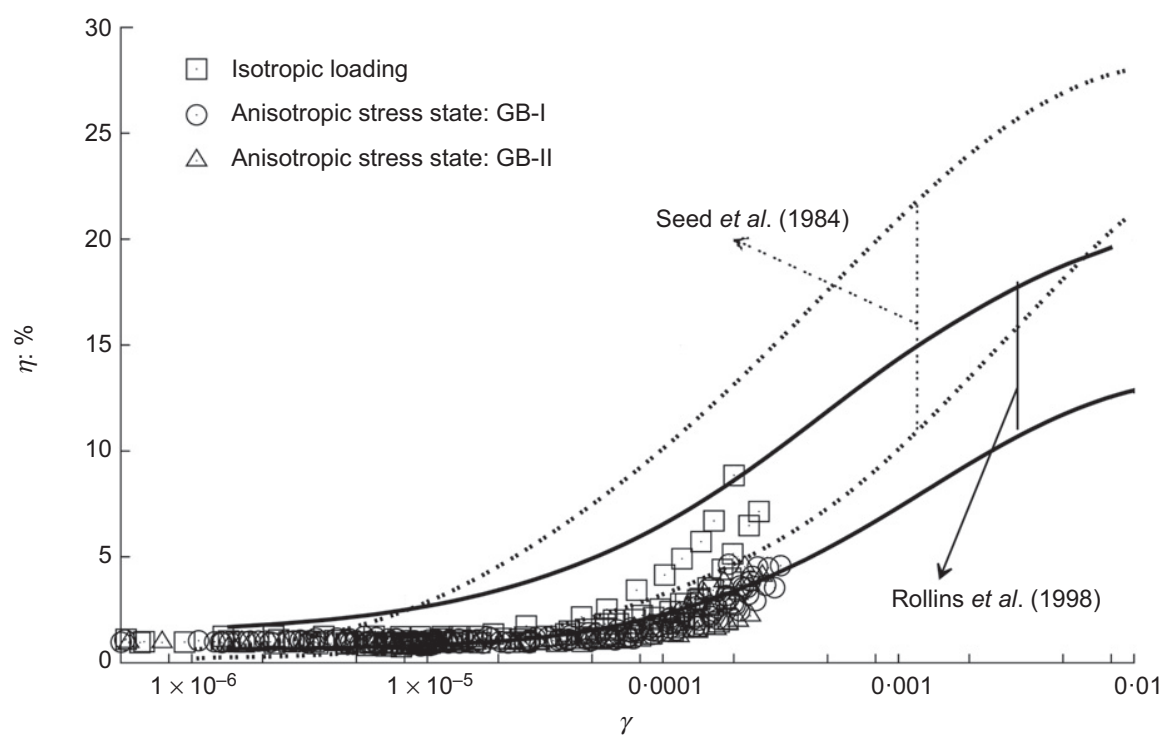

(b)

Fig. 10. (a) $G(\gamma) / G_{\max }$ plotted against $\gamma$; (b) $\eta(\gamma)$ plotted against $\gamma$, in glass bead samples subjected to all of the stress states in comparison with the published data for cohesionless soils

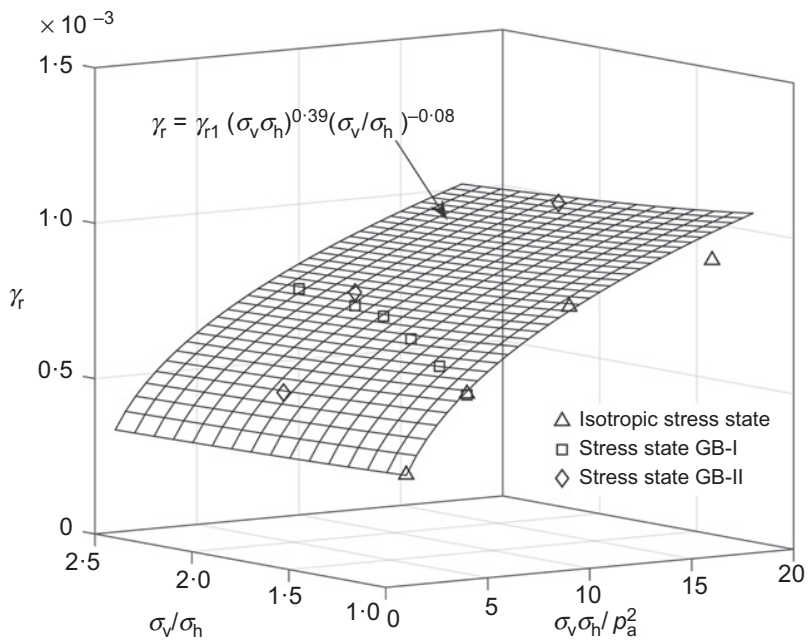

Fig. 11. $\gamma_{\mathrm{r}}$ plotted against $\sigma_{\mathrm{v}} \sigma_{\mathrm{h}}$ and $\sigma_{\mathrm{v}} / \sigma_{\mathrm{h}}$ for isotropic stress state and anisotropic stress states of GB-I and GB-II; the surface is equation (9)

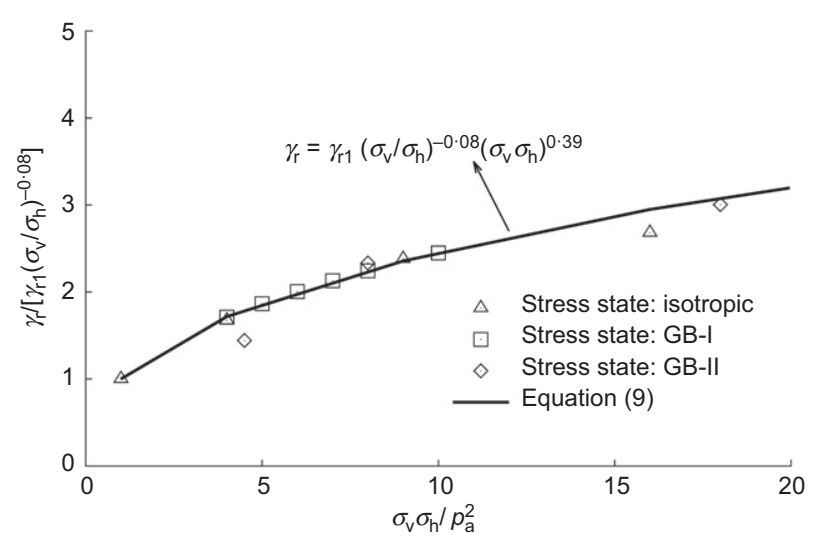

Fig. 12. Normalised $\gamma_{\mathrm{r}}$ plotted against $\sigma_{\mathrm{v}} \sigma_{\mathrm{h}} / p_{\mathrm{a}}^{2}$ for isotropic stress state and anisotropic stress states of GB-I and GB-II. The solid line is equation (9) with fitting parameters from Fig. 11 


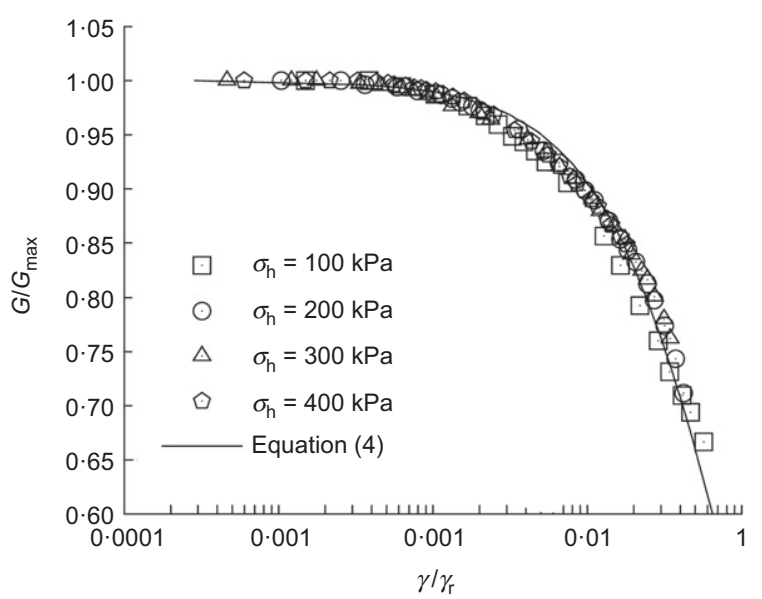

(a)

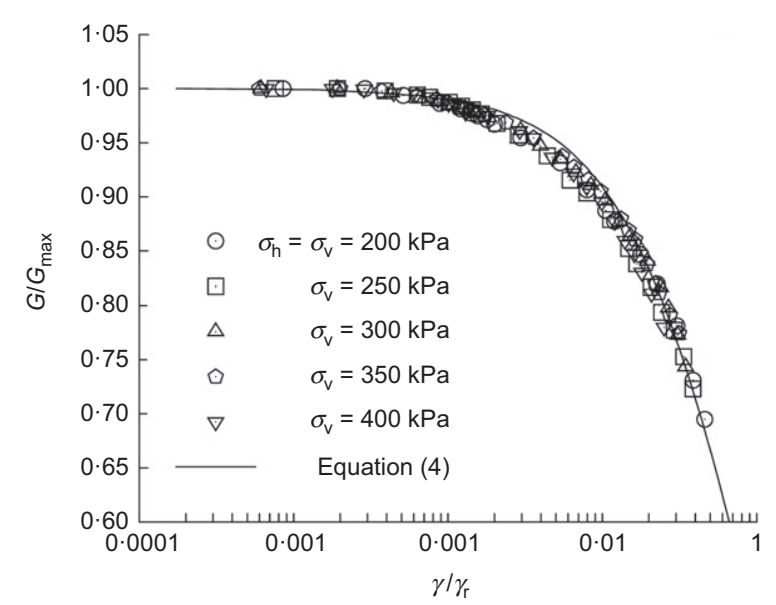

(b)

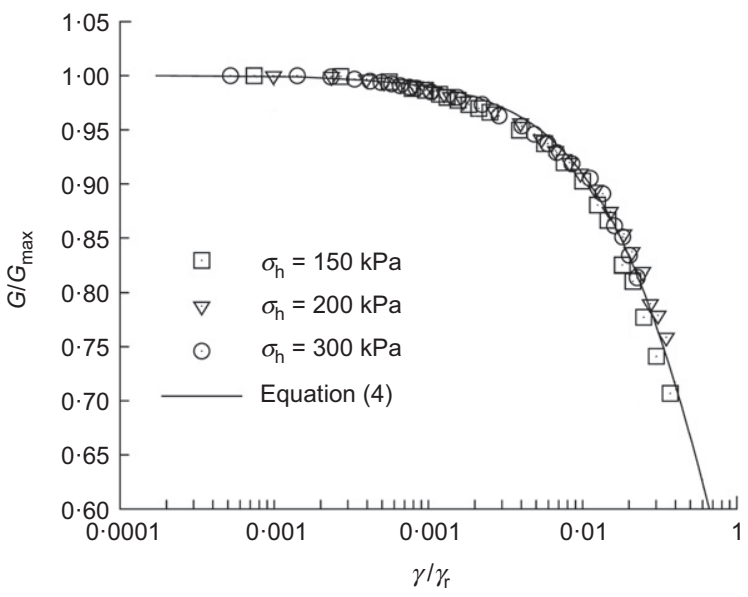

(c)

Fig. 13. Modulus ratio plotted against the normalised shear strain $\left(\gamma_{\mathrm{r}}\right.$ is from equation (9)), $e_{0}=0 \cdot 59$ and subjected to: (a) isotropic stress state; (b) stress state GB-I; (c) stress state GB-II. The solid line is equation (4), where $\gamma_{\mathrm{r}}$ is assumed to be $\gamma_{\mathrm{r}}$ for the isotropic stress state of $100 \mathrm{kPa}$

and anisotropic pressure component, $\sigma_{\mathrm{v}} / \sigma_{\mathrm{h}}$, in threedimensional space (Fig. 11). A surface, in the form of equation (9), was fitted to the data.

$$
\gamma_{\mathrm{r}}=\gamma_{\mathrm{r} 1}\left[\frac{\sigma_{\mathrm{v}} \sigma_{\mathrm{h}}}{p_{\mathrm{a}}^{2}}\right]^{m_{\mathrm{v}}}\left[\frac{\sigma_{\mathrm{v}}}{\sigma_{\mathrm{h}}}\right]^{m_{\mathrm{h}}}
$$

where $\gamma_{\mathrm{r}}$ is the reference shear strain and $\gamma_{\mathrm{r} 1}$ is the reference shear strain for an isotropic stress state of $100 \mathrm{kPa} . \sigma_{\mathrm{v}}$ and $\sigma_{\mathrm{h}}$ are the principal vertical and horizontal stress components, respectively; $m_{\mathrm{v}}$ and $m_{\mathrm{h}}$ are exponents of the compression pressure parameter and the anisotropic pressure parameter, respectively.

To obtain the best-fitted surface in Fig. $11, m_{\mathrm{v}}$ and $m_{\mathrm{h}}$ must be equal to 0.39 and -0.08 , respectively $\left(R^{2}=0.94\right)$. This means that $\gamma_{\mathrm{r}}$ has been slightly affected by the $\sigma_{\mathrm{v}} / \sigma_{\mathrm{h}}$ component. Fig. 12 shows a two-dimensional representation of the normalised $\gamma_{\mathrm{r}}$ plotted against the compression pressure parameter, $\sigma_{\mathrm{v}} \sigma_{\mathrm{h}}$. The solid line in this figure is equation (7), where $m_{\mathrm{v}}$ and $m_{\mathrm{h}}$ are equal to 0.39 and -0.08 , respectively. It is worth mentioning that $\gamma_{\mathrm{r} 1}$ could be an appropriate reference value in equation (9) as long as the effect of the stress-induced anisotropy on the fabric of the sample is not significant.

Therefore, with the empirical relation obtained by this study (equation (9)): (a) $G(\gamma)$ increases, $\eta(\gamma)$ decreases and their strain non-linearity decreases with an increase in the confining pressure parameter $\sigma_{\mathrm{v}} \sigma_{\mathrm{h}} ;(b) G(\gamma)$ decreases, $\eta(\gamma)$ increases and their strain non-linearity increases with an increase in the anisotropic stress state parameter $\sigma_{\mathrm{v}} / \sigma_{\mathrm{h}}$ from
$1 \cdot 0$ towards the value at failure. This means equations (2), (3) and (9) can be used together to estimate the value of reference shear strain for samples subjected to an anisotropic stress state.

\section{PREDICTION OF $G(\gamma) / G_{\max }$}

The normalised shear strain, $\gamma / \gamma_{\mathrm{r}}$, is a key parameter in the prediction of $G(\gamma) / G_{\max }$ using equations (1) and (4). To predict the $G(\gamma) / G_{\max }$, the shear strain was normalised with respect to $\gamma_{\mathrm{r}}$, which was obtained from equation (9) (see previous section 'Empirical relationships').

Figure 13 shows the $G(\gamma) / G_{\max }$ curves plotted against the normalised shear strain for the samples subjected to the isotropic (Fig. 13(a)) and anisotropic stress state (Figs 13(b) and 13(c)). In Fig. 13, the solid lines are the predicted results using equation (4), where the fitting parameters $a$ and $b$ were equal to 0.05 and 1 , and $\gamma_{\mathrm{r}}$ was determined with equation (9). Fig. 14 shows the damping ratio plotted against the normalised shear strain for all of the stress states (isotropic (Fig. 14(a)) and the anisotropic stress state (Figs 14(b) and 14(c))). The predicted curves, using equation (6), have been added as solid lines in these figures. The values of $\eta_{\min }, c_{1}$ and $c_{2}$ in equation (6) were equal to $0 \cdot 0102,0 \cdot 393$ and $0 \cdot 808$, respectively.

In the next analysis, the damping ratio, $\eta(\gamma)$, was normalised with respect to the minimum damping ratio, $\eta_{\text {min }}$. Shear strain, $\gamma$, was also normalised with respect to the reference shear strain, $\gamma_{\mathrm{r}}$. It is worth mentioning that $\gamma_{\mathrm{r}}$ was 


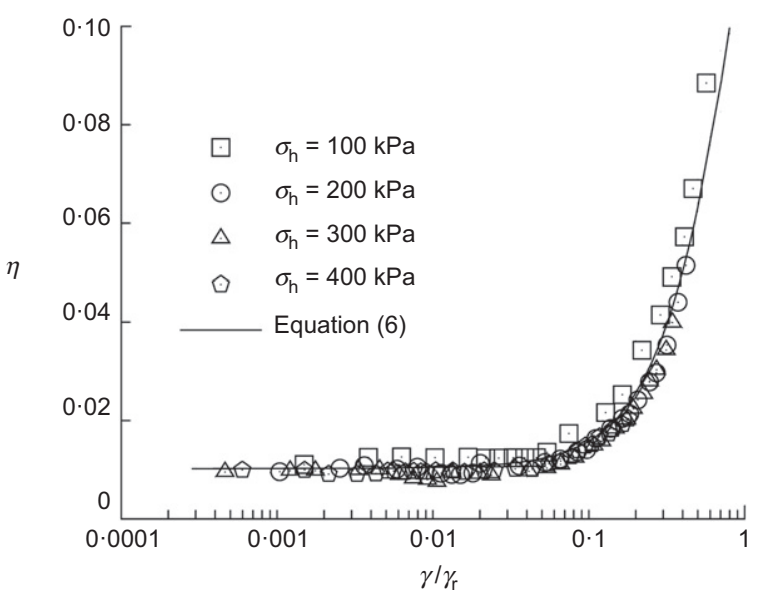

(a)

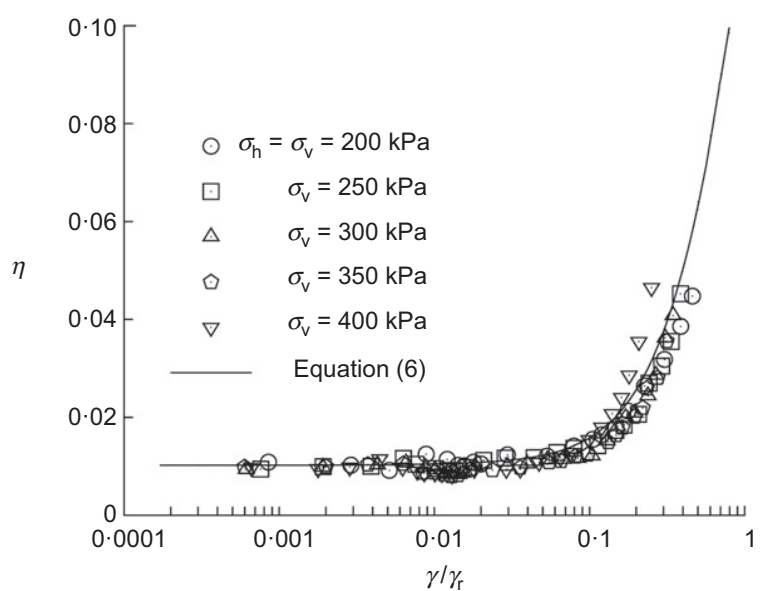

(b)

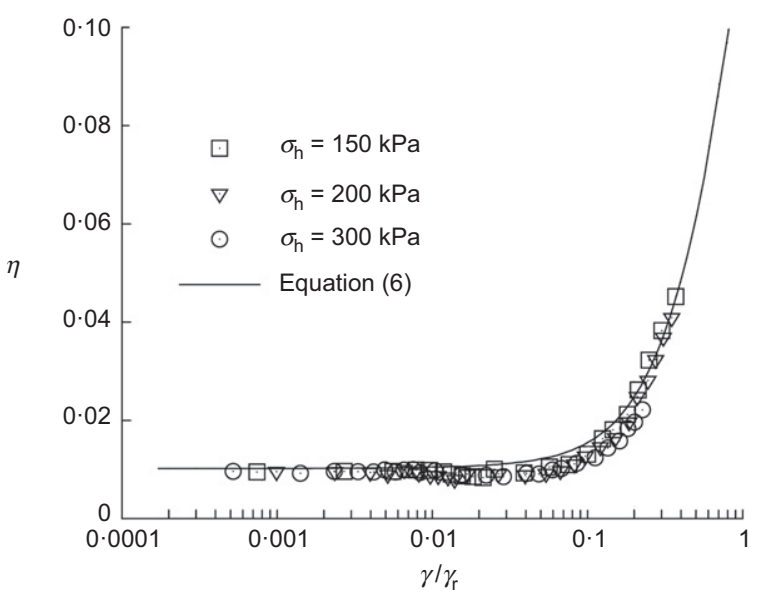

(c)

Fig. 14. Damping ratio plotted against the normalised shear strain $\left(\gamma_{\mathrm{r}}\right.$ is from equation (9)), $e_{0}=0 \cdot 59$ and subjected to: (a) isotropic stress state; (b) stress state GB-I; (c) stress state GB-II. The solid line is equation (6), where $\gamma_{r}$ is assumed to be $\gamma_{r}$ for isotropic stress state of $100 \mathrm{kPa}$ and $G(\gamma) / G_{\max }$ is from equation (4)

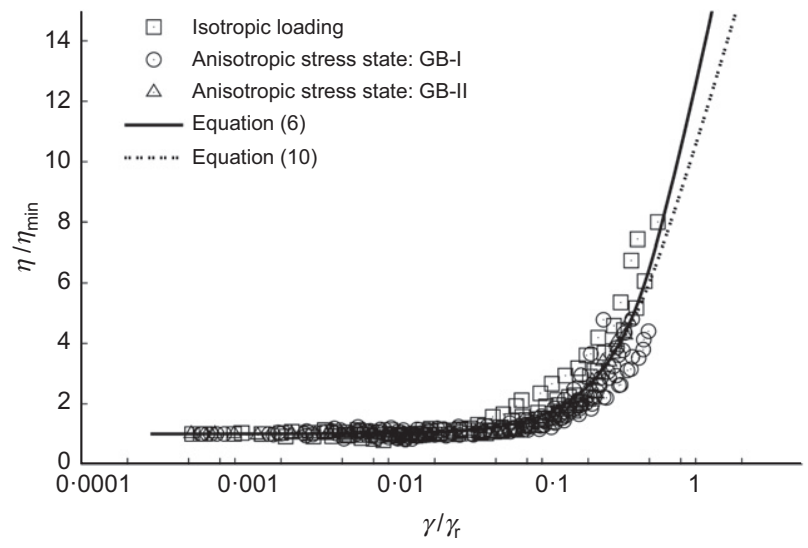

Fig. 15. Normalised damping ratio plotted against normalised shear strain for samples subjected to isotropic stress state, anisotropic stress states of GB-I and GB-II

estimated using equation (9). Normalised damping ratio was plotted against $\gamma / \gamma_{\mathrm{r}}$ for all of the samples in Fig. 15 . A curve in the form of equation (10) can be fitted to all of the data.

$$
\frac{\eta(\gamma)}{\eta_{\min }}=\Lambda\left[\frac{\left(\gamma / \gamma_{\mathrm{r}}\right)}{1+\left(\gamma / \gamma_{\mathrm{r}}\right)}\right]^{\Gamma}+1
$$

where $\Lambda$ and $\Gamma$ are fitting parameters, $\eta_{\min }$ is the minimum damping ratio and $\gamma_{\mathrm{r}}$ is the reference shear strain. The solid line in Fig. 15 is equation (6) with fitting parameters determined using polynomial regression of data in $\eta(\gamma)-G$ $(\gamma) / G_{\max }$ plots $\left(\eta_{\min }, c_{1}\right.$ and $c_{2}$ are equal to $0 \cdot 0102,0 \cdot 393$ and $0 \cdot 808$, respectively). The dashed line is equation (10), where $\Lambda$ and $\Gamma$ are 28 and $1 \cdot 6$, respectively.

It is worthwhile to mention that equations (4) and (10) are based on the reference shear strain. The reference shear strain is estimated through equation (9), and calibrated based on the experimental data from the current study. However, the fitting parameters of these models must be calibrated for other soils. $\gamma_{\mathrm{r}}$ is challenging; therefore, Yniesta \& Brandenberg (2016) showed that $\gamma / \gamma_{\mathrm{r}}$ can be replaced by stress ratio $\left(\tau / \sigma_{\mathrm{v}}\right.$, where $\tau=G \gamma$ and $\sigma_{\mathrm{v}}$ is vertical stress) for the interpretation of experimental data.

\section{THE EFFECT OF THE STRESS STATE ON $\Delta H-\gamma$ CURVES}

Two non-contact transducers were mounted on the top of the actuator in the resonant column device (Fig. 1). These non-contact transducers were used to record the vertical deformation (settlement) of the sample during vibration. Fig. 16 shows the effect of the stress path on the settlement of the sample, $\Delta H$, plotted against the amplitude of the shear strain during the resonant column test. Fig. 16(a) indicates that the settlement of the sample plotted against the shear 


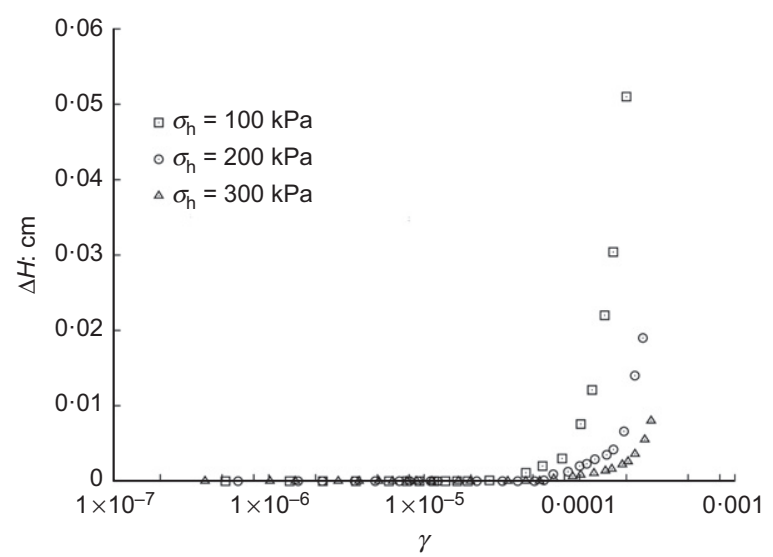

(a)

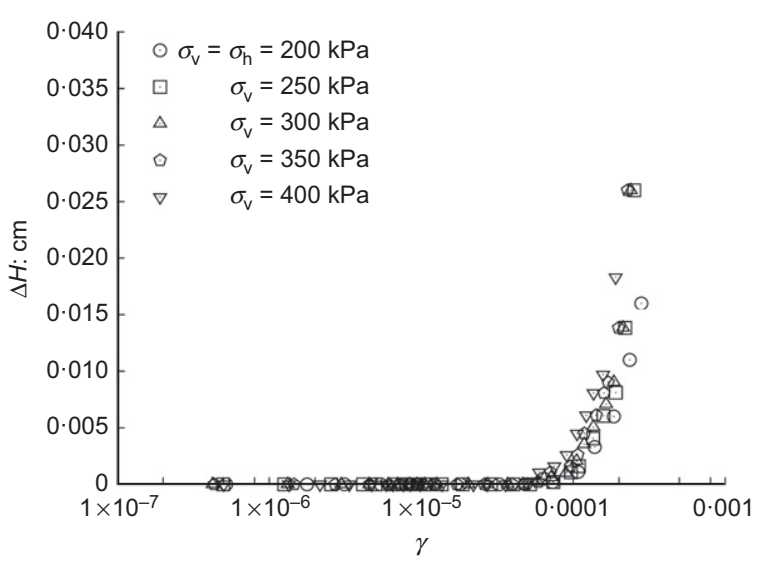

(b)

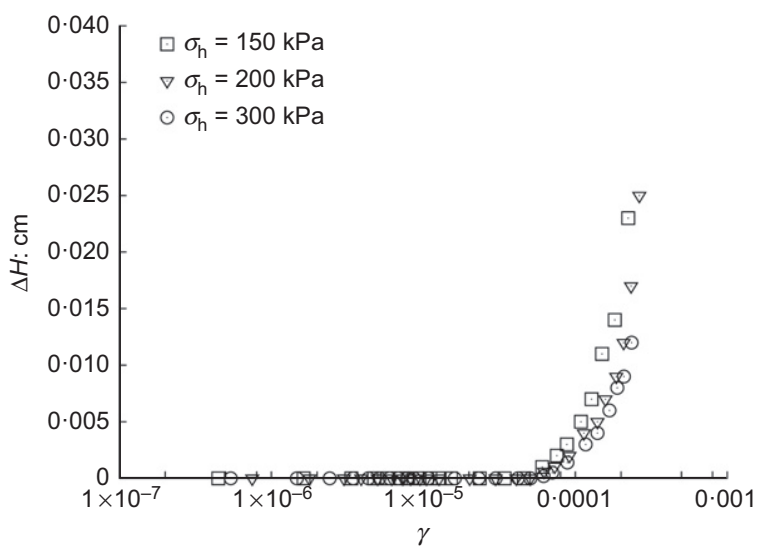

(c)

Fig. 16. Settlement of sample, $\Delta H$, plotted against the shear strain, $e_{0}=0.59$ and subjected to: (a) isotropic stress state; (b) stress state GB-I; (c) stress state GB-II

strain decreases with an increase in the confining pressure for the sample subjected to isotropic loading. Furthermore, this figure reveals the shear strain that the settlement of the sample initiates, $\gamma_{\mathrm{st}}$, increases with an increase in the isotropic confining pressure. Fig. 16(b) shows the settlement of the sample increases with an increase in the vertical stress for stress state GB-I and $\gamma_{\text {st }}$ decreases with an increase in the vertical stress. From Fig. 16(c), it can be concluded that the settlement of a sample decreases with an increase in the confining pressure for stress state GB-II and $\gamma_{\mathrm{st}}$ increases with an increase in the mean effective stress.

\section{DISCUSSION FROM A MICROSCOPIC PERSPECTIVE}

The small-strain properties of granular materials depend on the microstructural properties, particularly the particle and contact properties. However, for a given material, particle properties may remain the same and contact properties may make a major contribution to the small-strain properties of granular packing at the macroscopic level (e.g. Santamarina \& Aloufi, 1999).

Chang \& Liao (1994) and Otsubo et al. (2015) used a micromechanics based model to relate the shear modulus $\left(G_{\max }\right)$ of an assembly of randomly packed identical spheres to normal $\left(K_{\mathrm{N}}\right)$ and tangential $\left(K_{\mathrm{T}}\right)$ stiffness at contact points. Chang \& Liao (1994) proposed a model (equation (11)) to predict maximum shear modulus of granular packing, which is a function of the contact characteristics (details can be found in Chang \& Liao (1994) and Otsubo et al. (2015)).

$$
G_{\max }=\frac{2 N R^{2} K_{\mathrm{N}}}{3 V}\left(\frac{5 R_{\mathrm{K}}}{3+2 R_{\mathrm{K}}}\right)
$$

where $N$ is equal to the total number of contacts between particles in the volume of sample, $V$, and $R_{\mathrm{K}}$ is the stiffness ratio, which is calculated by

$$
R_{\mathrm{K}}=\frac{K_{\mathrm{T}}}{K_{\mathrm{N}}}=\frac{2(1-v)}{2-v}\left(1-\frac{f_{\mathrm{T}}}{\mu f_{\mathrm{N}}}\right)
$$

where $K_{\mathrm{T}}$ and $K_{\mathrm{N}}$ are tangential and normal stiffness; $v$ is the Poisson ratio of particles; $f_{\mathrm{T}}$ and $f_{\mathrm{N}}$ are shear and normal contact forces; and $\mu$ is the friction coefficient (Deresiewicz, 1953; Otsubo et al., 2015). DEM simulations have been carried out to assess the effect of the stress state on contact properties of granular mixtures, mainly on spherical particles (e.g. Cundall, 1988; Rothenburg \& Bathurst, 1989; Emeriault \& Chang, 1997; Yimsiri \& Soga, 2002; Magnanimo et al., 2008; Wang \& Mok, 2008; La Ragione \& Magnanimo, 2012a, 2012b; Goudarzy, 2015). These studies revealed that the normal contact force between particles increases with an increase in the isotropic stress. As is apparent from equations (11) and (12), the normal contact force and contact numbers have a positive effect on the stiffness. Therefore stiffness increases as long as isotropic stress increases. This is in agreement with the observed trends for the stiffness of samples subjected to an isotropic stress state.

The damping ratio is also affected by the mean effective stress. The dissipation of energy at contacts is one of the sources of energy losses in granular packing subjected to tangential oscillation. Equation (13) shows dissipation of energy between two particles subjected to a low amplitude of vibration (Johnson, 1985). This equation shows that the normal contact force has a negative effect on the dissipation of energy between two spherical particles subjected to a low amplitude of oscillation (equation (13)). 


$$
\Delta w=\frac{1}{36 \xi \mu f_{\mathrm{N}}}\left(\frac{2-v_{1}}{G_{1}}+\frac{2-v_{2}}{G_{2}}\right) Q_{0}^{3}
$$

where $\xi$ is the radius of contact; $Q_{0}$ is the amplitude of oscillation; $f_{\mathrm{N}}$ is the normal contact force; $\mu$ is the friction coefficient between two grains; and $v$ and $G$ are the Poisson ratio and shear modulus of grains. From this equation, it can be concluded that the damping ratio decreases with an increase in the normal contact forces, $f_{\mathrm{N}}$, between particles. This is in agreement with the observed trend for the damping ratio in samples subjected to an isotropic pressure.

In samples subjected to an anisotropic stress state, normal contact forces and shear contact forces increase along the adopted stress path (e.g. Cundall \& Strack, 1979; Rothenburg \& Bathurst, 1989; Emeriault \& Chang, 1997). The effect of anisotropic stress state on the shear stiffness and damping ratio depends on the magnitude of deviatoric stress. First, for low stress levels (low deviatoric stress), normal and shear contact forces increase with an increase in the anisotropic stress, but in low stress ratios normal contact forces are dominant. Therefore, stiffness increases slightly (equations (11) and (12)); however, the rate of the increase in stiffness is less than for isotropic loading, and can be attributed to the increase of shear contact forces during anisotropic loading. However, at higher stress levels, dilation will occur in the dense sample. Therefore, the coordination number and number of contacts will decrease and stiffness will significantly decrease.

\section{CONCLUSIONS}

The modulus degradation and damping ratio can both be affected by stress-induced anisotropic loading. The effect of anisotropic loading on $G(\gamma)$ and $\eta(\gamma)$ depends on the adopted anisotropic stress state. The experimental results showed that the effect of stress state GB-II (constant stress ratio) on the modulus ratio and damping ratio is more significant and obvious than that of stress state GB- I (confining pressure constant and vertical pressure variable).

Furthermore, reference shear strain data revealed that: (a) $G(\gamma)$ increases, $\eta(\gamma)$ decreases and their strain non-linearity decreases with an increase in the confining pressure parameter $\sigma_{\mathrm{v}} \sigma_{\mathrm{h}} ;(b) G(\gamma)$ decreases, $\eta(\gamma)$ increases and their strain non-linearity increases with an increase in the anisotropic stress state parameter $\sigma_{\mathrm{v}} / \sigma_{\mathrm{h}}$ from $1 \cdot 0$ towards the value at failure.

Empirical relations can also be used to predict the modulus degradation curves in soil elements subjected to anisotropic loading. The normalisations performed showed that a principal stress function $(f(\sigma))$ can be used with sufficient accuracy to find the reference shear strain $\left(\gamma_{\mathrm{r}}\right)$ for soil samples subjected to anisotropic loading. The damping ratio can be written as a function of the reference shear strain and minimum damping ratio.

\section{ACKNOWLEDGEMENT}

This study was performed within the framework of the project 'Influence of stress ratio on small-strain properties of sand with fines' funded by the German Research Council (DFG, project no. SCHA 675/20-1). The authors are grateful to the DFG for the financial support.

\section{NOTATION}

$a, b$ constant fitting parameters in equation (4)

$c_{1}$ and $c_{2}$ constant fitting parameters of equation (6)

$D$ diameter of sample

$D_{\mathrm{r}}$ relative density

$d$ diameter of particles $e_{\min }$ and $e_{\max }$ minimum and maximum void ratio

$f_{\mathrm{N}}$ normal contact force

$f_{\mathrm{T}}$ shear contact force

$G_{\max }$ maximum shear modulus

$G_{\mathrm{s}} \quad$ specific gravity of particles

$G(\gamma)$ shear modulus

$G_{1}$ and $G_{2}$ shear stiffness of particles 1 and 2 in equation (13)

$J$ polar mass moment of inertia of sample

$J_{\mathrm{L}} \quad$ polar mass moment of inertia of rotatable top part of resonant column device

$J_{0} \quad$ polar mass moment of inertia of rotatable bottom part of resonant column device

$K_{\mathrm{N}} \quad$ normal stiffness between two particles

$K_{\mathrm{T}} \quad$ shear stiffness between two particles

$L$ height of sample

$m_{\mathrm{v}}$ and $m_{\mathrm{h}}$ stress exponents in equation (9)

$N$ number of particles in equation (11)

$n$ stress exponents in equation (5)

$p_{\mathrm{a}}$ atmospheric pressure, $100 \mathrm{kPa}$

$p^{\prime}$ mean effective stress $\left(\left(\sigma_{\mathrm{v}}^{\prime}+2 \sigma_{\mathrm{h}}^{\prime}\right) / 3\right)$

$Q_{0}$ amplitude of oscillation

$q$ shear stress $\left(\sigma_{\mathrm{v}}^{\prime}-\sigma_{\mathrm{h}}^{\prime}\right)$

$R$ radius of particles

$R_{\mathrm{K}} \quad$ contact stiffness ratio, $K_{\mathrm{T}} / K_{\mathrm{N}}$

$r$ distance of point from the centre of sample in equation (7)

$V$ volume of sample

$v_{\mathrm{s}} \quad$ shear wave velocity

$W$ total energy

$x$ distance of point in the sample from base of the sample in equation (7)

$\alpha$ parameter equal to $\omega L / v_{\mathrm{s}}$

$\gamma$ shear strain

$\bar{\gamma}$ normalised shear strain with respect to volume of sample

$\gamma_{\text {et }}$ maximum shear strain that $G / G_{\max }=1$

$\gamma_{\mathrm{r}}$ reference shear strain

$\gamma_{\mathrm{r} 1}$ reference shear strain for isotropic pressure of $100 \mathrm{kPa}$

$\gamma_{\text {st }}$ shear strain that the settlement of sample start

$\Delta H \quad$ settlement of sample

$\Delta W$ dissipation of energy

$\varepsilon_{\mathrm{v}} \quad$ volumetric strain in the triaxial test

$\varepsilon_{1} \quad$ vertical strain in the triaxial test

$\eta_{\min }$ minimum damping ratio

$\eta(\gamma)$ damping ratio

$\theta_{\max }$ maximum rotation in top of sample during resonant column test

$\Lambda$ and $\Gamma$ fitting parameters of equation (10)

$\mu$ friction coefficient

$v$ Poisson ratio of particles

$v_{1}$ and $v_{2}$ Poisson ratio of particles 1 and 2 in equation (13)

$\xi$ contact radius

$\sigma_{\mathrm{h}}$ total horizontal stress component

$\sigma_{\mathrm{h}}^{\prime} \quad$ effective horizontal stress component

$\sigma_{\mathrm{v}}$ total vertical stress component

$\sigma_{\mathrm{v}}^{\prime} \quad$ effective vertical stress component

$\tau_{\max }$ maximum shear strength

$\phi$ friction angle

$\omega$ rotational frequency

\section{REFERENCES}

Chang, C. \& Liao, C. (1994). Estimates of elastic shear modulus for randomly packed granule. Appl. Mech. Rev. 47, No. 1S, 197-206.

Cundall, P. A. (1988). Computer simulations of dense sphere assemblies. In Micromechanics of granular materials (eds M. Satake and J. T. Jenkins), pp. 113-123. Amsterdam, the Netherlands: Elsevier.

Cundall, P. A. \& Strack, O. D. L. (1979). A discrete numerical model for granular assemblies. Géotechnique 29, No. 1, 47-65, http://dx.doi.org/10.1680/geot.1979.29.1.47.

Deresiewicz, H. (1953). Effects of an oscillating torsional couple on the contact surfaces of elastic spheres, Technical report. New York, NY, USA: Columbia University. 
Drnevich, V. P. (1978). Resonant-column testing: problems and solutions. In Dynamic geotechnical testing (eds M. L. Silver and D. Tiedemann), STP 654, pp. 384-398. West Conshohocken, PA, USA: ASTM International.

Emeriault, F. \& Chang, C.S. (1997). Anisotropic elastic moduli of granular assemblies from micromechanical approach. J. Engng Mech. 123, No. 12, 1289-1293.

Goudarzy, M. (2015). Micro and macro mechanical assessment of small and intermediate strain properties of granular material. PhD thesis, Ruhr-Universität Bochum, Bochum, Germany.

Gu, X. Q. \& Yang, J. (2013). A discrete element analysis of elastic properties of granular materials. Granular Matter 15, No. 2, 139-147.

Hardin, B. O. \& Drnevich, V. P. (1972a). Shear modulus and damping in soils: design equations and curves. Soil Mech. Found. Div. 98, No. 7, 667-692.

Hardin, B. O. \& Drnevich, V. P. (1972b). Shear modulus and damping in soils measurement and parameter effects. Soil Mech. Found. Div. 98, No. 6, 603-624.

Ishibashi, I., Chen, Y. C. \& Chen, M. T. (1991). Anisotropic behavior of Ottawa sand in comparison with glass spheres. Soils Found. 31, No. 1, 145-155.

Ishihara, K. (1996). Soil behavior in earthquake geotechnics. New York, NY, USA: Oxford University Press.

Johnson, K. L. (1985). Contact mechanics. Cambridge, UK: Syndicate of the University of Cambridge.

Kokusho, T. (1980). Cyclic triaxial test of dynamic soil properties for wide strain range. Soils Found. 20, No. 2, 45-60.

La Ragione, L. \& Magnanimo, V. (2012a). Contact anisotropy and coordination number for a granular assembly: a comparison of DEM simulations and theory. Phys. Rev. 85, No. 3, 031304, https://doi.org/10.1103/PhysRevE.85. 031304.

La Ragione, L. \& Magnanimo, V. (2012b). Evaluation of the effective moduli of an anisotropic, dense, granular material. Granular Matter 14, No. 6, 749-757.

Magnanimo, V., La Ragione, L., Jenkins, J. T., Wang, P. \& Makse, H. A. (2008). Characterizing the shear and bulk moduli of an idealized granular material. Europhys. Lett. 81, No. 3, 34006, https://doi.org/10.1209/0295-5075/81/34006.

Ng, T. T. \& Petrakis, E. (1996). Small-strain response of random arrays of spheres using discrete element method. J. Engng Mech. 122, No. 3, 239-244.

O’Donovan, J., O’Sullivan, C., Marketos, G. \& Muir Wood, D. (2015). Anisotropic stress and shear wave velocity: DEM studies of a crystalline granular material. Géotechnique Lett. 5, No. 3, 224-230, http://dx.doi.org/10.1680/jgele.15.00032.

Otsubo, M., O’Sullivan, C., Sim, W. W. \& Ibraim, E. (2015). Quantitative assessment of the influence of surface roughness on soil stiffness. Géotechnique 65, No. 8, 694-700, http://dx.doi. org/10.1680/geot.14.T.028.

Rollins, K., Evans, M. D., Diehl, N. B. \& Daily, W. D. (1998). Shear modulus and damping relationships for gravels. J. Geotech. Geoenviron. Engng 124, No. 5, 398-405.

Rothenburg, L. \& Bathurst, R. J. (1989). Analytical study of induced anisotropy in idealized granular materials. Géotechnique 39, No. 8, 601-614, http://dx.doi.org/10.1680/geot.1989.39.4.601.
Sadek, T., Lings, M., Dihoru, L. \& Wood, D. M. (2007). Wave transmission in hostun sand: multiaxial experiments. Rivista Italiana Geotecnica 41, No. 2, 69-84.

Santamarina, J. C. \& Aloufi, M. (1999). Small strain stiffness: a micromechanical experimental study. In Pre-failure deformation characteristics of geomaterials (eds M. Jamiolkowski, R. Lancellotta and D. Lo Presti), vol. 1, pp. 451-459. Lisse, the Netherlands: Balkema.

Santamarina, C. \& Cascante, G. (1996). Stress anisotropy and wave propagation: a micromechanical view. Can. Geotech. J. 33, No. 5, 770-782.

Seed, H. B., Wong, R., Idriss, I. \& Tokimatsu, K. (1984). Moduli and damping factors for dynamic analyses of cohesionless soils, Report No. UCB/EERC-84/14. Berkeley, CA, USA: University of California.

Stokoe, K. H., Darendeli, M. B., Andrus, R. D. \& Brown, L. T. (1999). Dynamic soil properties: laboratory, field and correlation studies. In Earthquake geotechnical engineering (ed. P. Seco e Pinto), vol. 3, pp. 811-845. Rotterdam, the Netherlands: Balkema.

Tatsuoka, F., Iwasaki, T. \& Takagi, Y. (1978). Hysteretic damping of sands under cyclic loading and its relation to shear modulus. Soils Found. 18, No. 2, 25-40.

Tatsuoka, F., Iwasaki, T., Fukushima, S. \& Sudo, H. (1979). Stress conditions and stress histories affecting shear modulus and damping of sand under cyclic loading. Soils Found. 19, No. 2, 29-43.

Vardanega, P. J. \& Bolton, M. D. (2013). Stiffness of clays and silts: normalizing shear modulus and shear strain. J. Geotech. Geoenviron. Engng 139, No. 9, 1575-1589.

Vucetic, M. \& Dobry, R. (1991). Effect of soil plasticity on cyclic response. J. Geotech. Engng 117, No. 1, 89-107.

Wang, Y. \& Mok, C. (2008). Mechanisms of small strain shear modulus anisotropy in soils. J. Geotech. Geoenviron. Engng 134, No. 10, 1516-1530.

Wichtmann, T. \& Triantafyllidis, T. (2013). Effect of uniformity coefficient on $G / G_{\max }$ and damping ratio of uniform to well graded quartz sands. J. Geotech. Geoenviron. Engng 139, No. 1, 59-72.

Wichtmann, T., Sonntag, T. \& Triantafyllidis, T. (2001). Über das Erinnerungsvermögen von Sand unter zyklischer Belastung. Bautechnik 78, No. 12, 852-865 (in German).

Yanagisawa, E. (1983). Influence of void ratio and stress condition on the dynamic shear modulus of granular media. In Advances in the mechanics and the flow of granular materials (ed. M. Shahinpoor), vol. II, pp. 947-960. Houston, TX, USA: Gulf Publishing.

Yimsiri, S. \& Soga, K. (2002). Application of micromechanics model to study anisotropy of soils at small strains. Soils Found. 42, No. 5, 15-26.

Yniesta, S. \& Brandenberg, S. J. (2016). Stress-ratio-based interpretation of modulus reduction and damping curves. J. Geotech. Geoenviron. Engng 143, No. 1, https://doi.org/10.1061/(ASCE) GT.1943-5606.0001585.

Yu, P. \& Richart, F. (1984). Stress ratio effects on shear modulus of dry sands. J. Geotech. Engng 110, No. 3, 331-345.

Zhang, X. J., Andrus, R. D. \& Juang, C. H. (2005). Normalized shear modulus and material damping ratio relationships. $J$. Geotech. Geoenviron. Engng 131, No. 4, 453-464. 